Chistyakova Guzel, Grishkina Anastasia, Remizova Irina, Melkozerova Oxana, Dankova Irina. Immunohistochemical studies on lymphocyte subpopulation in endometrium samples in women with infertility. Journal of Education, Health and Sport. 2020;10(6):20-27. eISSN 2391-8306. DOI http://dx.doi.org/10.12775/JEHS.2020.10.06.002

https://apcz.umk.pl/czasopisma/index.php/JEHS/article/view/JEHS.2020.10.06.002

https://zenodo.org/record/3878011

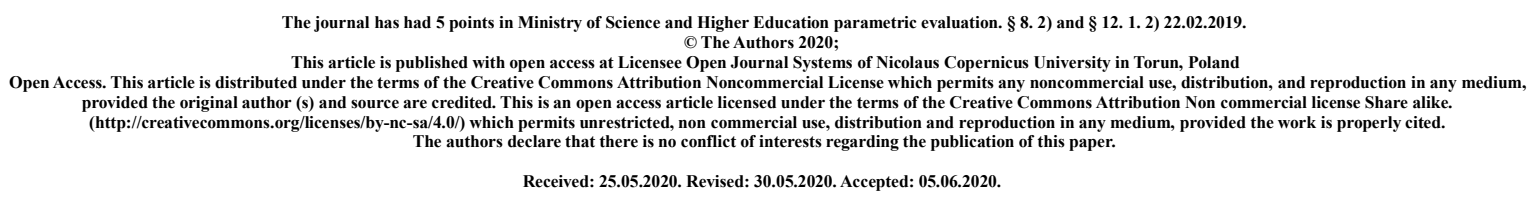

\title{
Immunohistochemical studies on lymphocyte subpopulation in endometrium samples in women with infertility
}

The Study performed in the Federal Research Institute of Maternity and Child Care, Russian Ministry of Public Health as part of the federal state program for the research.

Chistyakova Guzel Nuhovna - MD, Professor, Head of the Department of Immunology, Microbiology, Pathomorphology and Cytodiagnostics of the Ural Scientific Research Institute of Maternity and Child Care, Yekaterinburg, Russia ORCID 0000-00020852-6766. SPIN: 5436-8941.

Grishkina Anastasia Alexandrovna - Junior Researcher, Department of Immunology, Clinical Microbiology, Pathomorphology and Cytodiagnosis, Pathologist of the Department of Immunology, Microbiology, Pathomorphology and Cytodiagnostics of the Ural Scientific Research Institute of Maternity and Child Care, Yekaterinburg, Russia, ORCID 0000-0001$7433-2217$

Remizova Irina Ivanovna - PhD, Senior Researcher of the Department of Immunology, Microbiology, Pathomorphology and Cytodiagnostics of the Ural Scientific Research Institute of Maternity and Child Care, Yekaterinburg, Russia, ORCID 0000-0002-4238-4642, SPIN: $7222-4271$

Melkozerova Oxana Alexandrovna, MD, Deputy of Director for Science, Head of department reproductive functions preservation of the Ural Scientific Research Institute of Maternity and Child Care, Yekaterinburg, Russia, ORCID 0000-0002-4090-0578. SPIN: $5782-7283$

Dankova Irina Vladimirovna - Candidate of Medical Sciences, Senior Researcher Scientific advisory clinic, FSBI Ural Research Institute for Maternal and Child Care" of Ministry of Healthcare of Russian Federation, Yekaterinburg 620028; work phone: $+7(912)$ 287-74-65; e-mail: ivdankova@gmail.com, ORCID 0000-0002-7893-4722 eLibrary SPIN: 


\begin{abstract}
Uterine leucocytes have been thought to play a key role in endometrial pathology and infertility.

The aim of this study was to compare the amount of CD20+, CD3+, CD56+, CD138+ cells in the endometrium from women with simple endometrial hyperplasia without atypia and thin endometrium with the presence of infertility. 95 patients, with simple endometrial hyperplasia without atypia, thin endometrium, and women without endometrial pathology (controls) were selected as research subjects. Hematoxylin and eosin staining were performed on all endometrial biopsies. Immunohistochemical staining for CD20+, CD3+, CD56+, CD138+ cells was applied to all tissue samples. Additionally, the disease histories of patients were collected, were held clinical and laboratory tests. The number of CD20+ cells was higher in 1 group $(4,129 \pm 0,55)$ and 2 group $(5,872 \pm 0,85)$, compared to fertile patients $(1,353 \pm 0,16$, $\mathrm{p}<0.05)$. The ratio of $\mathrm{CD} 3+$ cells was higher in women with endometrial hyperplasia $(108,871 \pm 14,34)$ and lower in women with a thin endometrium $(36,388 \pm 3,83)$, compared to fertile patients $(72,848 \pm 6,11, \mathrm{p}<0.05)$. The study shows a notable increase of CD138+ in specimens with hyperplasia $(19,18 \pm 1,2)$ and thin endometrium $(20,81 \pm 1.45)$ compared to fertile patients $(1,02 \pm 0,5, \mathrm{p}<0.05$ in both cases $)$, and decreased of CD56-positive cells in stroma $(43,4 \pm 2,2 ; 33.6 \pm 2.8)$ and in glands $(7,4 \pm 1,2 ; 3.6 \pm 1,8)$ for hyperplasia and thin endometrium respectively compared to control group $(51,2 \pm 2,5 ; 14,8 \pm 0,9)$. Women, with endometrial hyperplasia, have larger populations of $\mathrm{CD} 20+, \mathrm{CD} 3+$, and $\mathrm{CD} 138^{+}$and decreased amount of $\mathrm{CD} 56+$ in the stroma and glandular cells, as for women with thin endometrium, they have large populations of CD20+ and CD138+ and small of CD3+, CD56+, but bough groups may be at greater risk for infertility disorders resulting from an inflammatory environment occurring during implantation or later during decidualization.
\end{abstract}

Key words: endometriosis, infertility, natural killer cells, thin endometrium, endometrial hyperplasia

\title{
Introduction
}

The complex structure of the endometrium accommodates a lot of distinct molecules and cells which contribute to, adhesion, trafficking, and signaling processes, cell distribution, that's why abnormalities in these areas could also potentially be involved in implantation failure [11]. Endometrial receptivity itself is important, although abnormalities in the window of implantation appearing in only a small proportion of patients. Studies have been reporting the unique properties of endometrial mononuclear cells in various reproductive phenomena, such as mucosal angiogenesis and trophoblast invasion. Although endometrial mononuclear cells play a role in endometrial integrity, skewed proportion and activation of these mucosal leukocytes potentially have negative impacts on endometrial receptivity [1]. Some studies have focused on the immune endometrial environment, the investigation of which may be 
more relevant than the analysis of peripheral blood. There is no doubt that the immune system, and in particular the uterine natural killer cells (uNK) and their coadjuvant cytokines plays a key role in the implantation process [14]

Lachapelle et al. reported as early as 1996 that, in endometrial biopsies, patterns of CD4 and CD8 positive $T$ cells can be intrinsically altered in recurrent miscarriage patients, as well as the deleterious presence of $\mathrm{B}$ cells and the negative impact of an increase in percentage CD56dim natural killer cells [10]. Klenzeris et al. reported that women with unexplained infertility had lower populations of CD8 $+\mathrm{T}$ cells and a higher amount of CD4+ T cells [8]. Mamedaliyeva et al. (2017) reported that patients with pregnancy loss in their past medical history demonstrate a decreased level of CD8 + lymphocytes, and the decrease is exacerbated as the incidence of miscarriages increases and in the presence of endometrial hypoplasia [12].

Uterine leucocytes have been thought to play a key role in endometrial pathology and infertility. Major leukocyte populations in human endometrium in pregnant and non-pregnant states include uterine NK cells (uNK, notably CD16-CD56brightNK), monocytes, and T cells. They have been thought to be associated with implantation failures, recurrent miscarriage or infertility due to either NK cell cytotoxicity or receptor/gene expression. NK cells cause cytotoxic effects by inducing lysis or apoptosis of the target cells mediated by the release of granular components within their cytoplasm or secretion of cytokines, such as TNF $\alpha$, IL10, and others. The human endometrium contains a substantial population of NK cells which vary in number and in proportion to the total number of endometrial stromal cells during the menstrual cycle. NK cells increase in number substantially in the mid-secretory phase and are the major endometrial lymphocyte population in the late secretory phase and the first trimester of pregnancy [13]. On the other side, the lineage of antibody-bearing lymphocytes including $\mathrm{B}$ cells and plasmacytes (PCs) is rarely found in the human endometrium [4]. B cells make up only $<1 \%$ of the entire leukocyte population in the non-pathologic human endometrium. Endometrial B cells are rarely seen in the functional layer (the portion that is shed during menstruation) but are found in the basal layer (the portion that persists across the menstrual cycle) as central cells in the lymphocyte aggregates surrounded by numerous CD8+ T cells and macrophages [15]. The significance of these endometrial B cells and lymphocyte aggregates not yet been fully explored. Kitaya K et al (2010) demonstrates that the abnormal expression of the multiple pro-inflammatory molecules involved in B-cell extravasation in the endometrium [5]. They also found that endometrial stromal plasmatic cells express multiple immunoglobulin subclasses (IgM, IgA1, IgA2, IgG1, and IgG2) with a predominance of IgG2 [2]. These excessive mucosal antibodies have the potential to affect the embryo implantation process negatively.

The aim of this study was to compare the amount of CD20+, CD3+, CD56+, CD138+ cells and expression of CD34 and VEGFr3 in the endometrium from women with simple endometrial hyperplasia without atypia and thin endometrium with the presence of infertility.

\section{Method of study}

Ninety five reproductive ages, women (18-45 years) were enrolled in the study. Thirty-one women had simple endometrial hyperplasia without atypia M-echo on day 19-22 of a cycle of $15 \mathrm{~mm}$ or more, thirty-two women with thin endometrium M-echo on day 19-22 of a cycle of $8 \mathrm{~mm}$ or less according to ultrasound data, ovulatory menstrual cycle, and 32 women had no history of infertility, recurrent pregnancy loss, or endometrial pathology (controls). The informed voluntary consent of the patient or her legal representative to participate in the study was obtained. Exclusion criteria were: age less than 18 and more than 45 years old, 
oncological diseases, somatic pathology in which gestation of pregnancy is contraindicated, other causes of infertility.

All the participants underwent a standard endometrial biopsy by Pipelle suction between days 21 to 24 of the menstrual cycle. Tissues subjected to immunohistochemical staining were fixed in 10\% neutral buffered formalin for 48 hours and embedded in paraffin and histological evaluation. Hematoxylin and eosin staining was performed. We stained the paraffin-embedded sections immunohistochemically using CD20 (a marker for B cells; 1:200 dilution); Novocastra CD3 PS1 (CD3e, a marker for $\mathrm{T}$ cells; 1:200 dilution), rabbit monoclonal antibody CD138 Ab-2 (Thermo Scientific, UK), rabbit monoclonal antibody CD56 (MRQ-42, manufactured by Cell Marque Corporation, USA), CD34 and vascular endothelial growth factor receptor 3 (VEGFr3) (Bond RTU Primary, Germany). Immunostaining was performed using a BOND-MAX autoimmunostainer (Leica Microsystems, Wetzlar, Germany). The reaction was manifested by the Dako Cytomation imaging system. Primary antibodies were visualized using the Super Sensitive Polymer-HPR Biotin-free detection System (Biogenex, USA). CD3, CD20, CD56, CD138 positive cells per 10 high-power fields were counted. VEGFr3 expression was investigated in the epithelium, stroma of the endometrium and vascular endothelium. Positive immunostaining in the form of staining of the membrane and cytoplasm of epithelial and endothelial cells. To analyze the results of IHC reactions, the $\mathrm{H}$-score histological counting method was used according to the formula: $\mathrm{HS}=1 \mathrm{a}+2 \mathrm{~b}+3 \mathrm{c}$, where $\mathrm{a}$ is $\%$ weakly stained cells, $\mathrm{b}$ is $\%$ moderately stained cells, $\mathrm{c}$ is $\%$ strongly stained cells, 1, 2, 3 - staining intensity, expressed in points. The expression of CD34 was recorded only in endothelial cells and was evaluated by counting vascular clefts per 10 high-power fields. We analyzed the number, perimeter, and area of capillaries, and calculate their percentage of the total area using ImageJ 1.50d (Java-based). Each woman was provided with an individual card, which included examination results with the study of complaints, medical and obstetric-gynecologic history, general and gynecological status data, conventional laboratory tests, and special examination methods, such as pelvic ultrasound, blood hormone levels, ELISA for infection.

The statistical analysis was carried out using the application program Statistica 10 (Microsoft World). The results were processed using various statistics and expressed in the form of $\mathrm{M} \pm \mathrm{m}$. The confidence estimation of differences in average data and relative indices was carried out with the use of the t-criterion (Student's criterion). The significant point is factored as $\mathrm{p}<0,05$.

Results

The average age of the women in the first group was $35,4 \pm 6,3$ in the second group with the thin endometrium $34,8 \pm 5,1$, in the control group - 34,6 $45,7(p>0,05)$ the groups were comparable in age. Characteristics of menstrual function have shown that the average age of

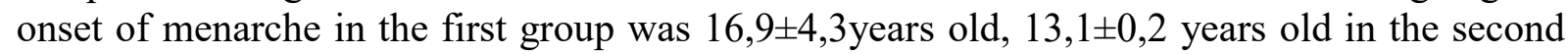
group and 13,0 $\pm 2,3$ in the control group. Menarche and the duration of the menstrual cycle in the observation groups did not have significant differences. The duration of menstruation was significantly shorter (up to 3 days) in women with endometrial hypoplasia (p1-3 $=0,0024$ ), which is explained by the presence of hypomenstrual syndrome. The continuance of infertility according to clinical data was $7,19 \pm 0,56$ years among women with simple endometrial hyperplasia without atypia and 6,88 $\pm 0,64$ years in women with a thin endometrium. Recurrent implantations failure were detected in $21(67,7 \%)$ cases in the first group and $18(56,3 \%)$ cases in the second group. The definition of recurrent implantation failure (RIF) remains 
controversial, generally is defined as the failure to conceive following two or three embryo transfer cycles, or cumulative transfer of $>10$ good-quality embryos.

In the interview with the patient, there were complaints of the absence of pregnancy for a year or more $(100 \%)$. There were also recorded complaints of periodic pain in the lower abdomen and lower back, meager short menstruation, painful menstruation; periodically occurring cyclic and acyclic bleeding and pathological discharge from the genital tract, having an unpleasant odor.

All patients underwent an ultrasound examination of the pelvic organs with Doppler velocimetry of the uterine vessels. The size of the uterus by ultrasound did not differ in patients of the first and second groups and was comparable with the controls. The thickness of the endometrial according to M-echo is significantly distinguishable: in patients with simple endometrial hyperplasia without atypia $-15,17 \pm 0,45 \mathrm{~mm}$, in a woman with thin endometrium

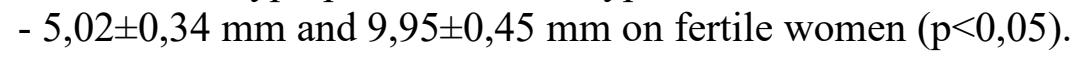

It was noted that in patients with endometrial hyperplasia a decrease in the relative number of neutrophils in blood samples was recorded $43,63 \pm 3,50 \%$ compared to $55,86 \pm 2,72 \%$ in the second group and $58,85 \pm 1,44 \%$ in the control group (p1-3<0.010). In women with endometrial hypoplasia, the study revealed a decrease of the relative number of eosinophils $1,51 \pm 0,19 \%$ compared to $2,70 \pm 0,30 \%$ in the first group and $3,30 \pm 0,58 \%$ in control group p $2-3$ $<0.010$.

Diffusely located lymphocytes with the rare formation of lymphoid follicles were found in endometrial samples in women of all however, there are no statistically significant differences between the groups. Estimates of immune cells in the stroma, infiltration of varying severity were more exposed in women with endometrial hyperplasia $-67.7 \%$, compared to controls $40.6 \%$ ( $p>0.0125)$. Table 1 presents the options for mononuclear infiltration.

Table 1 Mononuclear stromal infiltration in the endometrium of women in the studied groups

\begin{tabular}{|c|c|c|c|c|c|c|c|c|c|c|}
\hline \multirow[t]{3}{*}{ Group } & \multicolumn{10}{|c|}{ Mononuclear stromal infiltration } \\
\hline & \multicolumn{2}{|c|}{ None } & \multicolumn{2}{|c|}{ week } & \multicolumn{2}{|c|}{ moderate } & \multicolumn{2}{|c|}{ severe } & \multicolumn{2}{|c|}{$\begin{array}{l}\text { lymphoid } \\
\text { follicles }\end{array}$} \\
\hline & $\begin{array}{l}\mathrm{Ab} \\
\mathrm{s} .\end{array}$ & $\%$ & Abs. & $\%$ & Abs. & $\%$ & Abs. & $\%$ & Abs. & $\%$ \\
\hline $\begin{array}{l}\text { Group } 1 \text { simple } \\
\text { endometrial } \\
\text { hyperplasia without } \\
\text { atypia } n=31\end{array}$ & 10 & 32,3 & 14 & $\begin{array}{l}45, \\
2\end{array}$ & 2 & 6,5 & 2 & 6,5 & 3 & 9,5 \\
\hline $\begin{array}{l}\text { Group } 2 \text { thin } \\
\text { endometrium } n=32\end{array}$ & 15 & 46,8 & 13 & $\begin{array}{l}40 \\
6\end{array}$ & 4 & 12,6 & 0 & 0 & 0 & 0 \\
\hline Controls $n=32$ & 19 & 59,4 & 8 & 25 & 2 & 6,25 & 0 & 0 & 3 & 9,35 \\
\hline
\end{tabular}

It should be noted that in the endometrial biopsy of women with the simple endometrial hyperplasia, the level of fibrotization and fibroplastic transformation of stromal cells of the uterine mucosa was more pronounced than in the comparison group 
The analysis of the samples showed that the percentage of CD20+ cells in the endometrial samples was higher in women with endometrial hyperplasia $(4,129 \pm 0,55)$ and thin endometrium $(5,872 \pm 0,85)$, compared to fertile patients $(1,353 \pm 0,16, p<0.05)$. Kitaya $\mathrm{K}$. et. Al. (2012) noted in women with hyperplastic processes in the endometrium with miscarriage and infertility, plasmacytic infiltration [7].

Likewise, the ratio of $\mathrm{CD} 3+$ cells was higher in women with endometrial hyperplasia $(108,871 \pm 14,34)$ and lower in women with thin endometrium $(36,388 \pm 3,83)$, compared to fertile patients $(72,848 \pm 6,11, \mathrm{p}<0.05)$.

The immunoreactivity for CD138 was seen in the basolateral membrane of surface and glandular epithelium in all samples examined. The immunohistochemical results for plasma cells identified by CD138 in the stromal compartment show a notable increase in stroma of an endometrial biopsy specimen with hyperplasia $(19,18 \pm 1,2)$ and thin endometrium $(20,81 \pm 1.45)$ compared to fertile patients in which biopsies no plasma cells were observed, or less than five plasma cells were observed in each 400x magnification field $(1,02 \pm 0,5, \mathrm{p}<0.05)$, which can may confirm link between chronic endometritis and endometrial pathology [6].

The immune system can lead to fetal loss through activation of NK cells and macrophages. NK cells are directly involved in trophoblast lysis. Activation of macrophages enhances the production and secretion of cytokines that act on effector cells, including NK cells [7].

In a study by R.J. Kuon et al. 2016, revealed an increased circulation of NK cells in the peripheral blood and an increased level of expression of uNK cells in patients with habitual miscarriage. High levels of CD45 + CD3-DR + and CD45 + CD3 + CD8 + DR + peripheral blood lymphocytes may indicate that activated $\mathrm{NK}, \mathrm{B}$ and $\mathrm{T}$ cells provide cytokines for differentiation of uNK cells [9].

The immunoreactivity for CD56 (NK cells) was scattered as single cells or aggregates mainly in the stromal compartment, whereas some cells were noted in the epithelial areas. We revealed decrease in major CD56-positive cells in the groups with pathology of endometrium in stroma $(43,4 \pm 2,2 ; 33.6 \pm 2.8)$ and in glands $(7,4 \pm 1,2 ; 3.6 \pm 1,8$ for hyperplasia and thin endometrium respectively.), which showed as low cytotoxic activity compared to control group $(51,2 \pm 2,5 ; 14,8 \pm 0,9)$;

It was found that the expression of receptors for angiogenesis factors changed depending on the cause of infertility. The expression of CD34 was noted in the walls of the spiral arteries of medium and small caliber in all samples. Recent evidence suggests that CD34 is expressed by endothelial cells, vascular precursors, mesenchymal stem cells (MSC) and even epithelial progenitor cells The number of vessels expressing the CD34 receptor was significantly reduced in all women with infertility, however, the most pronounced almost two-fold decrease in their number was observed in women with simple endometrial hyperplasia At the same time, the total area of the vascular bed was significantly reduced in women with endometrial hyperplasia as well as in women with a thin endometrium. Cytoplasmic and membrane expression of VEGFr3 was observed in glandular cells, stromal cells, and vascular endothelium. There was also a significant decrease in the expression of VEGFr3 in the stroma in women of the second group compared with fertile women (Table 2). 
Table 2 The level of expression of factors angiogenesis in the structures of the uterine mucosa in patients with endometrial pathology

\begin{tabular}{|c|c|c|c|c|}
\hline \multicolumn{2}{|l|}{ Groups } & $\begin{array}{l}\text { Group } 1 \text { simple } \\
\text { endometrial hyperplasia } \\
\text { without atypia } n=31\end{array}$ & $\begin{array}{l}\text { Group } 2 \text { thin } \\
\text { endometrium } n=32\end{array}$ & Controls $n=32$ \\
\hline \multicolumn{2}{|c|}{$\begin{array}{l}\text { The number of } \\
\text { vessels in the field } \\
\text { of view }\end{array}$} & $\begin{array}{l}14,226 \pm 1,202 \\
\mathbf{P}_{\mathbf{1 - 3}}=\mathbf{0 , 0 0 0 1}\end{array}$ & $\begin{array}{l}16,194 \pm 1,356 \\
\mathbf{P}_{2-3}=\mathbf{0 , 0 0 0 1}\end{array}$ & $36,813 \pm 1,435$ \\
\hline \multicolumn{2}{|c|}{ Vessel area \% } & $\begin{array}{l}2,3 \pm 0,2 \\
\mathbf{P}_{\mathbf{1 - 3}}=\mathbf{0 , 0 0 0 1}\end{array}$ & $\begin{array}{l}2,3 \pm 0,3 \\
\mathbf{P}_{\mathbf{2 - 3}}=\mathbf{0 , 0 0 0 1}\end{array}$ & $3,8 \pm 0,2$ \\
\hline \multirow[b]{2}{*}{ VEGFr3 } & $\begin{array}{l}\text { Glands } \\
\text { (in } \\
\text { points) }\end{array}$ & $\begin{array}{l}271,94 \pm 9,78 \\
\mathrm{P}_{1-3}=0,108\end{array}$ & $\begin{array}{l}206,83 \pm 24,07 \\
P_{2-3}=1,0\end{array}$ & $223,25 \pm 10,74$ \\
\hline & $\begin{array}{l}\text { Stroma } \\
\text { (in } \\
\text { points) }\end{array}$ & $\begin{array}{l}207,29 \pm 17,85 \\
P_{1-3}=0,363\end{array}$ & $\begin{array}{l}81,50 \pm 20,09 \\
\mathbf{P}_{\mathbf{2 - 3}}=\mathbf{0 , 0 0 3}\end{array}$ & $161,88 \pm 6,22$ \\
\hline
\end{tabular}

\section{Conclusions}

The obtained data speak of the significant role of inflammatory endometrial changes in impaired implantation in patients with endometrial hyperplastic and hypoplastic processes. Women, with endometrial hyperplasia, have larger populations of $\mathrm{CD} 20+, \mathrm{CD} 3+$, and CD138+ and decreased amount of CD56+ in the stroma and glandular cells, as for women with thin endometrium, they have large populations of CD20+ and CD138+ and small of $\mathrm{CD} 3+$, CD56+, decreased stromal expression of VEGFr3, but both groups show signs of decreased angiogenesis and may be at greater risk for infertility disorders resulting from an inflammatory environment occurring during implantation or later during decidualization.

Authors report no conflicts of interest.

\section{References}

1. Bulmer JN, Williams PJ, Lash GE. Immune cells in the placental bed, Int. J. Dev. Biol. 2010;54:281-294. DOI: 10.1387/ijdb.082763jb.

2. Kitaya K., Tada Y., Hayashi T, Taguchi S., Funabiki M., Nakamura Y. Comprehensive endometrial immunoglobulin subclass analysis in infertile women suffering from repeated implantation failure with or without chronic endometritis. Am J. Reprod Immunol. 2014;72:386- 391. DOI: 10.1111/aji.12277

3. Kitaya K., Tada Y., Taguchi S. Local Mononuclear Cell Infiltrates in Infertile Patients With Endometrial Macropolyps Versus Micropolyps. Hum. Reprod.2012;27: 3474-3480. DOI: $10.1093 /$ humrep/des323.

4. Kitaya K, Yamaguchi $\mathrm{T}$, Yasuo $\mathrm{T}$, Okubo $\mathrm{T}$, Honjo $\mathrm{H}$ : Post-ovulatory rise of endometrial CD16(-) natural killer cells: in situ proliferation of residual cells or selective 
recruitment from circulating peripheral blood. J. Reprod Immunol.2007;76:45- 53. DOI: 10.1016/j.jri.2007.03.010.

5. Kitaya K., Yasuo T. Aberrant expression of selectin E, CXCL1, and CXCL13 in chronic endometritis. Mod. Pathol. 2010;23:1136- 1146. DOI: 10.1038/modpathol.2010.98.

6. Kitaya K., Yasuo T. Inter-observer and intra-observer variability in immunohistochemical detection of endometrial stromal plasmacytes in chronic endometritis. Experimental and therapeutic medicine. 2013;5(2):485-488. DOI: 10.3892/etm.2012.824

7. Kitaya K., Yoshihiro T., Sagiri T. Miyako F., Terumi H., Yoshitaka N. Local mononuclear cell infiltrates in infertile patients with endometrial macropolyps versus micropolyps. Human reproduction (Oxford, England). 2012;27: 3474-3480. DOI: 10.1093/humrep/des323

8. Klentzeris LD, Bulmer JN, Warren MA, Morrison L, Li TC, Cooke ID. Lymphoid tissue in the endometrium of women with unexplained infertility: morphometric and immunohistochemical aspects. Hum Reprod. 1994;47:646-652. DOI: 10.1093/oxfordjournals.humrep.a138564.

9. Kuon RJ, Vomstein K, Weber M. The "killer cell story" in recurrent miscarriage: Association between activated peripheral lymphocytes and uterine natural killer cells. J. Reproductive Immunology. 2016;11:123-134. DOI: 10.1016/j.jri.2016.11.002.

10. Lachapelle MH, Miron P, Hemmings R, Roy DC. Endometrial T, B, and NK cells in patients with recurrent spontaneous abortion. Altered profile and pregnancy outcome. $\mathrm{J}$ Immunol., 1996;156(10):4027-4034.

11. Lucas ES, Dyer NP, Murakami K, Hou Lee Y, Chan YW, Grimaldi G, Muter J, Brighton PJ, Moore JD, Patel G, Chan JKY, Takeda S, Lam EWF, Quenby S, Ott S, Brosens JJ. Loss of endometrial plasticity in recurrent pregnancy loss. Stem Cells., 2016;34( 2): 346356. DOI: $10.1002 /$ stem.2222.

12. Mamedaliyeva N. M., Kurmanova A. M., Lokshin V. N., Kurmanova G. M. ,. Issenova S. S. Clinical and immunological parallels in pregnancy loss. Gynecological Endocrinology., 2017;33(1):5-7. DOI: 10.1080/09513590.2017.1404238.

13. Menaldo G., Uterine Natural Killer Cells In Proliferative Endometrium Of Infertile Women. The World Congress on Controversies in Obstetrics, Gynaecology and Infertility, Morressier 2019

14. Van Mourik MS, Macklon NS, Heijnen CJ. Embryonic implantation: cytokines, adhesion molecules, and immune cells in establishing an implantation environment. J Leukoc Biol., 2009;85(1):4-19. DOI: 10.1189/jlb.0708395.

15. Yeaman GR, Guyre PM, Fanger MW, Collins JE, White HD, Rathbun W, Orndorff KA, Gonzalez J, Stern JE, Wira CR: Unique CD8+ T cell-rich lymphoid aggregates in human endometrium. J Leukoc Biol., 1997;61: 427- 435. 